\title{
(5) \\ Perú: lucha por la integración pluricultural y el peligro de la modernidad en la educación
}

Peru: struggle for multicultural integration and the danger of modernity in education

Perú: Lucha por la integración pluricultural y el peligro de la modernidad en la educación

\section{Erik Felix}

Universidad Nacional de Educación Enrique Guzmán y Valle, La Cantuta (Perú) https://orcid.org/0000-0003-1786-9215

DOl: https://doi.org/10.35622/j.rep.2021.04.002

Recibido 02/12/2020/ Aceptado 16/11/2021

\begin{abstract}
RESUMEN. La presente investigación tiene por objetivo reflexionar entorno al qué hacer de la comunidad educativa en general, esto con el propósito de integrar a todo estudiante en una política pedagógica propia y amplia, escuchando todas las voces, de cada comunidad, y por supuesto, sus problemáticas. Para ello se realizó un breve recorrido histórico dando a conocer las principales políticas educativas desde la fundación de la República hasta la actualidad, remarcando el afán de los sucesivos gobiernos por implantar modelos pedagógicos extranjeros en su erróneo intento por "modernizar" a la nación. Asimismo, se analizó cómo este proceso de modernización, en el actual contexto neoliberal, no proporciona soluciones reales al universo pedagógico peruano, y por el contrario, se muestra excluyente y fuera del contexto nacional, donde se hace necesario que nos identifiquemos como país pluricultural, con diversas lenguas, costumbres, historias, tradiciones, etc.
\end{abstract}

PALABRAS CLAVE: Historia de la educación, educación indígena; pluriculturalidad; modernidad; integración educativa.

ABSTRACT. The present research aims to reflect on what to do in the educational community in general. This is to integrate all students in their own and broad pedagogical policy, listening to each community's voices, and of course, their problems. For this, a brief historical tour was made, revealing the main educational policies from the founding of the Republic to the present, highlighting the desire of successive governments to implement foreign pedagogical models in their erroneous attempt to "modernize" the nation. Likewise, it was analyzed how this modernization process does not provide real solutions to the Peruvian pedagogical universe in the current neoliberal context. On the contrary, it is exclusive and outside the national context, where we must identify ourselves as a multicultural country, with different languages, customs, stories, traditions, etc.

KEYWORDS: History of education, indigenous education; multiculturalism; modernity; educational integration.

RESUMO. A presente pesquisa pretende refletir sobre 0 que fazer na comunidade educacional em geral, isto com 0 propósito de integrar todos os alunos em sua própria e ampla política pedagógica, ouvindo todas as vozes de cada comunidade e, claro, seus problemas. Para isso, foi feito um breve percurso histórico, revelando as principais políticas educacionais desde a fundação da República até a atualidade, evidenciando o desejo de sucessivos governos de implementar modelos pedagógicos estrangeiros em sua errônea tentativa de "modernizar" a nação. Da mesma forma, foi analisado como esse processo de modernização, no atual contexto neoliberal, não oferece soluções reais para 0 universo 
pedagógico peruano, pelo contrário, é exclusivo e fora do contexto nacional, onde é necessário que nos identifiquemos. como um país multicultural. com diferentes línguas, costumes, histórias, tradições, etc.

PALABRAS CLAVE: História da educação, educação indígena; multiculturalismo; modernidade; integração educacional.

\section{INTRODUCCIÓN}

En la actualidad, el contexto educativo peruano se ha visto desnudado por las grandes brechas existentes entre los estudiantes de las grandes ciudades y los que se encuentran fuera de ellas, indudablemente, este es un enorme problema a resolver, puesto que no puede existir una educación con mirada nacional, si no tomamos en cuenta las carencias y necesidades de cada comunidad alejada, si no tomamos en cuenta a toda cultura relegada y/o invisibilizada desde el centro.

Indudablemente debemos mirar hacia el actual modelo pedagógico, cuáles son sus propuestas y objetivos, desarrollando entorno a ello una crítica constructiva que nos permita reflexionar como sociedad en su conjunto, qué es lo que debemos hacer. Es claro que el constructivismo, actual paradigma educativo, no deja de lado la integración educativa, es más, el propio CNEB (2016) dentro de los ocho niveles con el que cuenta la competencia Construye Interpretaciones Históricas, jamás deja a un costado el aspecto local y su importancia para las aulas, por el contrario, en cada nivel está presente, sin embargo, debemos tener en cuenta que esto no se refleja en la práctica, puesto que aquello no está dentro del principal propósito de modelo en mención, sino el de desarrollar una competencia, un aspecto mecánico y no sentimental del rescate ancestral.

En consecuencia, se hace urgente voltear nuestras miradas hacia nuevos paradigmas educativos con la finalidad de encontrar mejores alternativas, aclarando pues que este nuevo paradigma, debe construirse con las propias comunidades y no alejadas de ellas, puesto que como se verá, históricamente las comunidades alejadas han sido relegadas y no consultadas acerca de sus carencias y necesidades, brotando así una herida por curar, una igualdad que aparentemente no se logrará si no se realiza una reflexión intensiva.

Asimismo, debemos tomar en cuenta que el proceso de modernización, sin duda juega un papel fundamental en estas brechas educativas que parecen irreversibles, la tecnología 
llegó al país y se estableció en el centro, quedando fuera del radar educativo todo aquel que no esté a la "moda tecnológica", por tanto, es claro que las comunidades indígenas, que se encuentran en la cola, en la eterna espera por un equipo que les facilite el proceso de enseñanza-aprendizaje, pero sobre todo, a la espera de este paradigma educativo que los escuche y que les considere como parte de la nación, son las que se ven más perjudicadas.

\section{MÉTODO}

En la presente investigación, se aplicó el método hermenéutico, el cual, además de analizar los datos recolectados, realiza un ejercicio reflexivo "sobre la interpretación adoptada como vía del comprender los fenómenos sociales, ofreciendo criterios para elaborar una crítica de las tradiciones metodológicas utilizadas en las ciencias sociales" (Darío, como se citó en Maldonado, 2016, p. 9).

\section{DESARROLLO Y DISCUSIÓN}

\section{Breve historia de la política educativa peruana, sistema fragmentado}

Es claro que, si no entendemos y conocemos el proceso histórico a estudiar, no comprenderemos las grietas y/o falencias de la actualidad, para ello, es necesario hacer un breve recorrido histórico acerca de lo que abordaremos, es decir, de las políticas educativas aplicadas e implantadas desde la fundación de la República peruana hasta la actualidad.

Iniciamos entonces este breve recuento histórico cuestionándonos si fue 1821 el año del gran quiebre a favor de la integración del Perú como nación, o en contraparte, fue un año sin mayor sobresalto para las poblaciones alejadas de la "ciudad de los reyes", es decir, un grave continuismo del sistema excluyente virreinal. Así, tenemos como punto de partida desde luego a San Martín, quien según Apaza (2016), “puso énfasis en la instrucción pública como la primera necesidad de las sociedades y consideró la integración de las poblaciones indígenas, a quienes, dijo no debe llamarse indígenas, sino peruanos" (p. 117).

Claramente, entorno al enunciado rescatado surgirían muchas críticas, partiendo por el hecho innegable que, como es sabido, el propio indígena no se sentía miembro o parte del "nuevo" sistema criollo, es más, una cantidad importante consideraba que se les habían traicionado, que el "nuevo" sistema republicano era en esencia lo mismo, pidiendo incluso, 
el retorno de los peninsulares a nuestro territorio, como, por ejemplo, en el caso de los indígenas de lquicha.

Así, debemos tener en cuenta que, el primer intento por integrar la nación por parte de San Martín, fue un claro fracaso, originándose una nueva tensión que se incrementó cuando Bolívar decidió nuevamente cobrar tributos, aunque claro, con nuevo nombre, "contribución personal", surgiendo así un largo enfrentamiento entre una población indígena que esperaba el retorno de su glorioso pasado tahuantinsuyano, y el criollo, ansioso de controlar a plenitud la economía colonial.

Claro está que, para algunos historiadores, como Heraclio Bonilla, lo dicho anteriormente, respecto a la ansiedad del criollo por controlar su propia economía, no se aplicaría en el Perú, puesto que, desde su óptica, nuestra independencia no fue un proceso ganado del todo, sino por el contrario, un proceso concedido desde el exterior. Sin embargo, lo que no se puede cuestionar es que, una vez lograda la "independencia", las políticas a seguir desde la óptica indígena serán totalmente distintas a la del criollo, siendo los primeros en mención, los que, sin contar con la fuerza militar de su lado, los marginados del nuevo modelo criollo. Entonces, podemos decir que el inicio de la República nos dejó a dos mundos divididos y con distintos planes para la nación, la integración habría pensado cualquier indígena o criollo, sería el mayor reto que enfrentaría el país, y sin duda, pasado ya doscientos años, irónicamente, lo es.

Ahora, ¿Por qué insistir tanto con la integración?, Es claro que si no logramos alcanzar dicha categoría, la educación jamás será igualitaria, jamás democrática, por tanto, lo que San Martín nos dejó fue un esbozo incluso demagógico de integración, pero al fin y al cabo, una ruta a seguir, una ruta en busca de la articulación, de sabernos como nación diversa pero a la vez unificada, ¿Cómo lograrlo?, Desde la educación, desde las escuelas, con una férrea política educativa preocupada por lo diverso.

Sin detenernos en nuestro breve recorrido histórico, llegamos al gobierno de Ramón Castilla, quien "realizó una obra de estructuración, organización e integración nacional (...). Concibió a la educación como el instrumento esencial para el desarrollo nacional, dictando la Ley 
Orgánica de Enseñanza" (Apaza, 2016, p. 117). Sin embargo, también podemos decir que, en tiempos tan convulsionados militarmente, producto de los constantes enfrentamientos que sostuvo con sus opositores políticos, como con Echenique (siendo sin duda el más importante). la educación siguió en espera, puesto que los dictámenes a favor de la universalidad educativa, quedó simplemente en eso, en meros dictámenes inaplicados.

Así damos inicio a la República aristocrática, el periodo que "consolidó un orden político nacional basado en la exclusión de los campesinos indígenas [Con la excusa] de la estabilidad política y desarrollo económico" (Heilman, 2018, p. 34), que no era otra cosa que intentar afianzarse en el poder político y económico los emergentes aristócratas peruanos. En esa misma línea Zapata (2016), aclara que aquellos años significaron para el Perú una segregación cultural, y también cívico/ciudadano, puesto que solo tenían derecho a votar los que sabían leer y escribir en castellano, concretándose así "la exclusión de las poblaciones indígenas: quechuas, aimaras y grupos étnicos selváticos, que constituían la mayoría del país" (p. 77).

"Fue el gobierno de José Pardo (1904-8) el que se delineó y puso en práctica una primera reforma educativa de envergadura que ordenó y organizó lo pre existente y le dio un norte para los desarrollos futuros" (Apaza, 2016, p. 117). La cita en mención es pues en relación, a que por ejemplo, la educación primaria pasó a convertirse en la prioridad del estado, implantando su gratuidad y su obligatoriedad, sumando a este mandato el reparto gratuito de materiales para mejorar la enseñanza. Sin embargo, hay algo que nos llama poderosamente la atención y que será analizado en el siguiente capítulo: "Todo esto se hizo con el apoyo de pedagogos franceses, belgas y especialmente alemanes" (Apaza, 2016, p.117).

Pero si los proyectos educativos de Pardo se hicieron con "colaboración" de los países "superiores y modernos", lo hecho por Leguía en política educativa, fue una intensificación de dicha incursión extranjera en nuestras aulas, no sin antes mencionar que el nuevo presidente, estableció el nivel secundario obligatorio. Así pues, para 1921, habían ya copado las instancias educativas superiores, los pedagogos norteamericanos, quienes “asumieron la Dirección General y las Direcciones Regionales del Ministerio de Educación 
lo que significó el giro del enfoque intelectualista, academicista e integral europeo al enfoque norteamericano más pragmático y articulado con el desarrollo económico" (Apaza, 2016, p. 118).

Los programas educativos norteamericanos, sin embargo, no cubrían el territorio nacional, desatándose en consecuencia y producto del descontento indígena, el movimiento Tahuantinsuyo. Dicho movimiento surgido en Ayacucho terminó expandiéndose por Cusco, Puno, Arequipa, Huancavelica, Junín, Apurímac, Piura, Ica, Huánuco, en un intento por recuperar su identidad y los derechos indígenas, proponiendo "un cambio revolucionario del Estado-nación, que transformara a los (...) indios en ciudadanos peruanos, iguales al resto (...) buscaba poner fin a la pobreza extrema, la exclusión política y la denigración sociocultural [a través de la educación]" (Heilman, 2018, p. 73).

Es más, este movimiento, en represalia a los abusos cometidos por parte de los letrados o tinterillos (como los propios indígenas los llamaban) "se alzaron para matar a los que saben leer y escribir (...) puesto que (...) a inicios del siglo XX, dichas habilidades eran sinónimo de poder político formal” (Heilman, 2018, p. 87). Así pues, con tan solo leer la proclama del movimiento podemos notar la aspiración del Indígena por su educación: "queremos educarnos y educar a nuestros hijos. Necesitamos escuelas y más escuelas hasta los últimos rincones de nuestros ayllus" (Kapsoli, como se citó en Heilman, 2018, p. 88).

La educación significaba poner fin a los engaños por parte de los letrados, poder leer lo que firmaban sería sin duda un gran logro, un paso hacia su liberación, "significaba ser capaz de comunicarse en español, ya que la educación bilingüe no se intentó en el Perú sino hasta la década de 1970" (Heilman, 2018, p. 88). En ese sentido, los miembros del comité Tahuantinsuyo manifestaban: "antes de ser avezados hay que saber leer y escribir... los gamonales saben que su régimen llegará a su fin el día en que el indio sepa leer y escribir" (Cadena, como se citó en Heilman, 2018, p. 89).

Sin embargo, no solo los movimientos sociales en busca de reivindicaciones caracterizaban a los indígenas, sino también su entrega por el autofinanciamiento. Así, para 1936, y para dar un ejemplo, los migrantes Ayacuchanos estacionados en Lima, conformaron la Sociedad 
Progresista Mutualista de Carhuanca y Anexos, en la que "se comprometieron a organizar una escuela nocturna (...) ofrecer charlas educativas [y] cumpliendo con este compromiso (...) los miembros de la sociedad donaron más de 400 soles" (Heilman, 2018, pp. 138-139). Es imposible dejar de mencionar el gobierno de Óscar R. Benavides (1933-1939), quién creó el Ministerio de Educación, desarrollando "una amplia obra social, en alguna medida inspirada en el fascismo italiano (...) que pretendía generar una política nacionalista que reforzara los vínculos entre los sectores populares y el Estado" (Zapata, 2016, p. 87), ello con el propósito de ganar réditos con la población. Benavides construyó pues numerosas escuelas primarias tratando de hacerla universal, sueño de los tantos gobernantes del siglo XX. Asimismo, intensificó la educación preescolar, en donde su señora esposa, Francisca Benavides, tuvo gran participación.

En la época de Benavides la política educativa rural estaba dirigida a civilizar al indígena, asumiendo que era un ser necesario de cultura porque su mentalidad aborigen era concebida como atrasada y se creía que el estado debía ayudar a dejarla atrás. Desde la República Aristocrática estaba en curso un serio intento por castellanizar a la población rural a través de la escuela pública, imponiendo el ideal occidental y cristiano como base de la nacionalidad peruana (Zapata, 2016, p. 90).

Otro proyecto educativo a mencionar es el surgido en 1940 con la presencia de Prado, quien "dio un gran impulso la educación técnica y normal y además estableció la educación infantil para niños de 4 a 7 años, (...) la secundaria común de cinco años con ingreso a la opción técnica, normal o artística" (Apaza, 2016, p. 118). Debemos sin embargo mencionar, que lo más importante de este periodo gubernamental, es el hecho de que "se abrieran las puertas del magisterio a las clases medias, que le imprimieron a la carrera magisterial un nuevo rostro social. Ya no era una profesión para las élites" (Apaza, 2016, p. 118).

Haremos aquí un alto para analizar qué tanto beneficiaron estos "nuevos rostros" a la educación indígena, así, volveremos nuestros pasos sobre Ayacucho, tierra en la que luego del movimiento Tahuantinsuyo, no cesó la lucha por la educación igualitaria. Según Heilman (2018) los Ayacuchanos "ansiaban la educación, pero frecuentemente odiaban a los educados" (p. 155). El problema entonces no solo se resume en carencia, "ya que algunos estudiantes estaban recibiendo clases en la cárcel pública, mientras que todos los demás 
estudiaban en la plaza central" (Heilman, 2018, p. 155). Si no, además, en el enfrentamiento contra los propios educadores, que, a propósito, no era el único, estaban además los hacendados, férreos opositores a la educación indígena, puesto que se veían directamente perjudicados al perder mano de obra para sus tierras.

Continuando con el enfrentamiento indígena-educador, se puede apreciar que éstos "nuevos rostros sociales" no significaron un gran cambio hacia adelante, por el contrario, surgió un nuevo enfrentamiento para el indígena, denunciando constantemente a docentes y directores porque "hacían que sus alumnas sirvieran como domésticas de sus casas (...) [además] que el profesor venía cuando quería” (Heilman, 2018, p. 157). Casos más macabros aún encontramos en lo narrado por Heilman (2018) "Ios asaltos sexuales por parte de los maestros a las alumnas también era un problema real [éstos eran acusados] pero siempre declarados inocentes por el tribunal" (Heilman, 2018, p. 159).

La carencia educativa en las provincias por tanto generó la gran migración hacia la capital, siendo el gobierno de Bustamante y Rivero (1945), el que enfrente esta problemática, teniendo la misión de "alfabetizar y castellanizar a los migrantes, pero a la vez, [esto] se constituiría en [un] factor de exclusión por motivos étnico culturales” (Apaza, 2016, p. 118). Bustamante optó por establecer la educación secundaria gratuita, con la finalidad de expandir este nivel, logrando según cuadros numéricos comparativos, significativos avances en relación a los años anteriores. Sin embargo, el gran problema estuvo en la no construcción de nuevos centros educativos, así como también, la no implementación de los centros con las que ya se contaba, a ello le podemos sumar el hecho concreto de que la carrera docente no era, como hasta hoy, una de las profesiones adecuadamente remuneradas, por lo tanto, cubrir las plazas pedagógicas serían una verdadera hazaña.

La urgencia de construir nuevos colegios fue tomada por Odría, quién apuntando a mejorar el sistema educativo nacional, con su lema "salud, educación y trabajo", aprobó su Plan Nacional de la Educación, creando el Fondo de Educación Nacional para financiar los gastos educativos: "se crearon 55 Grandes Unidades Escolares [y] nuevamente se imitó los modelos norteamericanos que procuraban mejorar la enseñanza de las ciencias y expandir la educación técnica" (Apaza, 2016, p. 118). Si para Benavides su prioridad era la educación 
primaria, para Odría fue la secundaria, no dejando de lado el tema de la profesionalización del magisterio, para lo cual "construyó la entonces Escuela Nacional de Educación de la Cantuta, que buscó profesionalizar la carrera magisterial" (Zapata, 2016, p. 102)

En seguida, con el afianzamiento de la nueva clase social tomando el ministerio, se estableció durante el gobierno de Prado (1958) la Federación Nacional de Educadores del Perú (FENEP), que posteriormente pasaría a denominarse Sindicato Único de Trabajadores en la Educación del Perú (SUTEP) para 1972.

Ya para el gobierno de Velasco, sin duda tendríamos que hablar de una gran reforma, donde se:

Abordó la educación como una cuestión política y económica-social, que debía comprometer la participación organizada de la comunidad vinculándola con el desarrollo y el trabajo y planteaba que no se podía cambiar la estructura económica, social y cultural del país si no se reformaba su educación (Apaza, 2016, p. 119).

El proyecto educativo de Velasco, estaba acompañado de Ley de la Reforma Educativa, la misma que disponía la creación de nuevos distritos escolares, la ampliación del acceso a la educación, la introducción de la educación bilingüe, cambio de currícula y nuevos métodos de enseñanza. El punto de Aquiles de esta reforma estuvo sin embargo en la Ley 006-69, la cual establecía que todo aquel estudiante de secundaria desaprobado en algún curso pagara por éste obligatoriamente el monto de 100 soles al mes, suma por demás exagerada de costear para cualquier campesino, originándose un gran levantamiento en todo el país, principalmente en Ayacucho (Huanta).

En el campo histórico, Velasco es sin duda uno de los personajes más controversiales, las diversas posturas existentes en relación a su gobierno nos atraparían en una discusión inacabable, por lo que nos remitiremos a lo práctico de su mandato, en la que se puede asegurar que se incrementaron el número de estudiantes, no solo en el Nivel Básico Regular, sino además, en las universidades. Asimismo, se construyeron una cantidad considerable de escuelas en zonas rurales, como también se implementaron algunos centros con computadoras, culminando con capacitaciones más exhaustivas para los docentes.

Con el fin del Gobierno Revolucionario de las FF.AA. Belaúnde optó por considerar en su 
programa político a los campesinos, a lo que llamaría, cooperación popular, "en las que los hombres y mujeres rurales participarían en la reforma del Perú, al combinar su trabajo con los recursos materiales del estado [entre los cuales figuraba las escuelas]" (Heilman, 2018, p. 189). Sin embargo, en la práctica la carga laboral "recaía sobre los hombros de los campesinos más pobres [y cuando éstos] exigieron ser remunerados [las autoridades los sancionaban] por su actitud destructiva en obras de bien común" (Heilman, 2018, p. 206). Con el inicio de la guerra entre las fuerzas del orden y Sendero Luminoso, la educación y sus avances se cayeron en picada, según Barrantes y Peña (2009), todo lo que se había logrado en integración educativa se terminó por perder de manera acelerada: "el panorama previo al inicio de la violencia en el campo educativo nos muestra varios puntos importantes: (...) la expansión sin precedentes de la escuela pública a lugares donde antes jamás había llegado" (p. 16). La pérdida no solo correspondía a la ausencia de estudiantes que migraban de las zonas de conflicto, sino también, de los propios docentes, quienes fueron perseguidos constantemente, tanto por Sendero Luminoso como por las propias fuerzas del orden, al ser estigmatizados como terroristas, obligándolos a "dejar sus puestos de trabajo frente al avance del conflicto" (Barrantes y Peña, p. 114).

Este retroceso en el campo educativo significó para Fujimori una gran oportunidad de cambiar radicalmente el modelo, algo que finalmente concretó, claro está, no de manera positiva, puesto que se caracterizó por ser un régimen "centralista, burocratizado y reglamentarista, el cual solo alentó la expansión de la educación privada en todos los niveles. Así la oferta educativa privada creció significativamente, sobre todo en el nivel superior. Sin embargo, no se ensayaron fórmulas descentralizadoras" (SINEACE, 2011, p. 120).

Como es sabido, Fujimori "rediseñó de forma radical el Estado peruano, desapareciendo el Estado empresario con afanes redistributivos, esfumando la herencia de Velasco (...) e imponiendo el Estado neoliberal regulador y subsidiario del mercado" (Zapata, 2016, p. 114). Hoy podemos decir que, si bien el país ha propuesto un sistema educativo inclusivo y pluricultural, adecuándose a las problemáticas y necesidades de cada región y garantizando el derecho a la educación universal, los modelos extranjeros nos han absorbido, llevándose consigo el alma del Perú ancestral. Así pues, debemos entender que la "articulación no debe significar homogeneidad de procesos formativos o de modelos institucionales, sino la 
posibilidad de conciliar la existencia de múltiples recorridos educativos en función de las capacidades y demandas de las personas" (SINEACE, 2011, p. 9).

En nuestro recorrido, no hemos dejado de ver en cada gobernador de turno, intentar aplicar un sistema pedagógico extranjero, "hemos sido permanentes copiadores (...) hemos pasado de estar en manos de las misiones belgas, alemanas y norteamericanas, a depender de las prioridades establecidas por los organismos de cooperación técnica y financiera internacionales" (SINEACE, 2011, p. 121). Es hora de mirar al Perú desde adentro, desde sus raíces, de escuchar a los que no tienen voz en el "mundo de lo formal", escuchar a todos, y emprender a elaborar un currículo acorde a nuestras problemáticas y carencias, respetando cada cultura, cada forma de vida, cada historia.

\section{Efecto modernidad: extinción de lo diverso}

Debemos ser claros y conceptualizar el término modernidad, puesto que sin duda es el punto clave para entender y comprender nuestro sistema educativo y cómo ello afecta las aulas escolares en su conjunto. Para dicha definición tomaremos a Dussel (2008), quién la conceptualiza como "el manejo de la centralidad de Europa en el Sistema- Mundo. [Por tanto], para que haya centro tiene que haber periferia (...) Nosotros [Latinoamérica] somos (...) los bárbaros a ser modernizados desde el origen. No hay Modernidad sin bárbaro" ( $p$. 27).

En consecuencia, podemos decir sin temor a equivocarnos que, los llamados especialistas pedagógicos, venidos de Europa occidental y de Norteamérica, intentaron a todas luces, "modernizar" al Perú, situándose en la cima de toda civilización periférica, es decir, superiores a los que no se encuentran en el centro-poder. Así, "el proceso de modernización y globalización toma a los no-globalizados y a los no-modernizados como inferiores, como gente inculta, que tiene que llegar al nivel de ellos" (Dussel, 2008, p. 27).

Lo contundente de lo descrito líneas arriba nos lleva rápidamente a ubicar al Perú dentro de los países periféricos-tercermundistas, en otras palabras, dentro de los países que optan por traer modelos educativos extranjeros, porque claro, son "superiores" a lo que nosotros podríamos elaborar, y por tanto, el "modelo" a seguir, olvidando que la diversidad cultural 
de nuestro territorio, no puede estar sometido a un parámetro universal-único occidentalista, desde donde inevitablemente, lo plurinacional se pierde.

¿Resuelve hoy en día el modelo constructivista las problemáticas de nuestra Amazonía, de los andes, o tan siquiera de la propia Lima de todas las sangres?, Es claro que la respuesta es un no contundente. Las distintas realidades y problemáticas de cada población, que a su vez cuentan con su propia cultura, tradición e historia, son claramente ocultadas o invisibilizadas por el "único y verdadero" modelo educativo exterior, por aquel modelo moderno que "civilizará" a los "barbaros", pudiendo percibir que la política de Benavides, sigue tan latente como antes, donde la cuestión educativa rural:

Estaba dirigida a civilizar al indígena, asumiendo que era un ser necesario de cultura porque su mentalidad aborigen era concebida como atrasada y se creía que el estado debía ayudar a dejarla atrás (...) imponiendo el ideal occidental y cristiano como base de la nacionalidad peruana (Zapata, 2016, p. 90).

En ese mismo sentido, Mariátegui (2007), en sus análisis aún vigentes en un país casi sin avances, hizo énfasis en que la educación peruana, no tiene espíritu nacional:

Tiene más bien, un espíritu colonial y colonizador. Cuando en sus programas de instrucción pública el Estado se refiere a los indios, no se refiere a ellos como a peruanos iguales a todos los demás. Los considera como una raza inferior. La República no se diferencia en este terreno del Virreinato (p. 87).

Debemos detenernos en lo mencionado acerca del espíritu colonial y colonizador, puesto que no escapa en nada a la verdad, en nuestro breve recorrido histórico, hemos podido dar cuenta de cómo se optaba y se opta por traer modelos pedagógicos extranjeros sin intentar armar uno propio, uno en donde se escuchen a todas las voces. Por el contrario, se intentaba castellanizar a los indígenas implicando esto la pérdida de su cultura. Así pues, "la reorganización de la enseñanza tiene que estar dirigida por sus propios hombres. La intervención de especialistas extranjeros no puede rebasar los límites de una colaboración" (Mariátegui, 2008, p. 71).

Es preciso entonces hacer hincapié en las distintas manifestaciones pluriculturales 
existentes en el Perú, para ello tomaremos como el ejemplo más claro al idioma, a la lengua madre de cada localidad, que irónicamente, en lugar de ser y utilizarlo como uno de los motores para reconocernos, aceptarnos e integrarnos, es un punto en contra para la educación "formal" del país, esto debido a que, la migración hacia la capital, absorbe toda cultura, llevándola a la discriminación, terminando finalmente por desecharla. Así nos lo hacen saber Sucari, Aza, Anaya y García (como se citó en Vargas y Pérez, 2019):

muchos jóvenes de la región Puno que abandonan la comunidad o lugar de origen por un periodo determinado, dejan de hablar las lenguas andinas quechua y aimara; optando la lengua castellana, por la oficialidad de uso del castellano en diversos sectores institucionales del estado y en la sociedad urbana misma, inclusive obviándolo en su lugar de reuniones familiares o sociales (p. 245).

Para Jopen, Gómez, y Olivera (2014), esto enfrenta al país en una gran disyuntiva, puesto que poner sobre las carpetas a las distintas lenguas significaría una convulsión para los estudiantes del habla castellana, en el sentido de, al ser éstos últimos mayoría en las "escuelas formales", y dentro de un país alienado, rechazarían (como se comprueba en estudios) lo autóctono, "modernizando" irremediablemente a los migrantes, y éstos a su vez, harían lo propio en su retorno a las localidades alejadas, perdiéndose de a pocos lo singular, siendo en consecuencia urgente y necesario, además de las campañas emprendidas de la aceptación de lo propio como algo relevante, el hecho de crear escuelas sólidas en las localidades quechuas - Aymaras, donde nada se pierda, donde no haya la necesidad de migrar.

Con la anterior descrito, está claro que el problema se agudiza aún más cuando dentro del propio Ministerio de Educación, a través de CNEB (2016), se deja de lado a las culturas locales, esto a pesar de que si bien es cierto lo mencionan, lo hacen de manera demasiado superficial, comprobándose ello al darle una breve mirada al texto escolar repartido por el Estado: "en los estándares curriculares, estándares de aprendizaje, contenidos transversales y otros, poco o casi nada se incluye sobre la valoración a las culturas quechua - aimara: historia, autores o representantes y su legado" (Vargas y Pérez, 2019, p. 245). Volvemos entonces a caer en los mismos errores históricos en materia educativa, se adopta desde el gobierno un modelo extranjero, como lo es hoy el constructivismo, y no se preocupa 
realmente por darle un soporte técnico y económico a toda cultura relegada, donde finalmente los lugares "modernos" del país se encargan de desechar todo lo pluricultural. Así las cosas, Vargas y Pérez (2019) se cuestionan: “¿qué nos identifica como peruanos?” (p. 246). Sin duda pues, este, además de ser una gran pregunta, es un problema que hasta hoy en día no se ha podido resolver, puesto que la identidad terminó cambiándose por alienación, en un camino al parecer sin retorno, donde la juventud sigue bajo el firme pensamiento que lo de afuera es lo último y mejorado.

Así, [en] el Perú, [que] es cuna de múltiples culturas como la quechua y aimara, cuya cosmovisión es distinta a la afroperuana, shipiba o aguaruna, etc. (...) no es extraño que escuchemos contraponer culturas, como la cultura indígena vs. la occidental, o considerar a la nación quechua y aimara como algo distinto y antagónico a las otras culturas (Vargas y Pérez, 2019, p. 246).

Las escuelas por tanto deben ser ese espacio donde se reviertan los protagonismos, donde lo local pase a ser el eje motor de movimiento y de ilación hacia lo nacional y mundial. Las escuelas deben estar en constantes cambios y modificaciones en pro de resolver los problemas más cercanos para luego enfocarse en el qué hacer nacional, "sin embargo en el Perú se aprecia una parálisis paradigmática, tanto en las instituciones educativas como en la sociedad" (Rojas, 2016, p. 262). Qué mejor entonces para comenzar a rescatar a lo local que la historia, valorando a sus personajes y sus acciones, concretando el sentido de pertenencia “y la valoración de la herencia cultural” (Rottenbacher, 2009, p. 80). Esto debido a que, como bien señalaron Ramírez et al. (2011).

Fortalecer la defensa de la identidad nacional en los jóvenes, resulta en los momentos actuales una razón de la que no se admite espera, si se tiene en cuenta que la identidad es un proceso, que no solo experimenta fortalecimiento en su dinámica y predominio sociocultural; también puede aminorarse e incluso disiparse (p. 89).

Existe en consecuencia, una clara necesidad en el Perú por cambiar y/o modificar el modelo pedagógico constructivista, romper con lo "moderno" que no da respuesta a nuestras problemáticas, intentar un nuevo mundo desde una renovadora y emancipadora educación, evocando nuevos contenidos pedagógicos, en donde el aspecto histórico local no esté en un segundo plano, incentivando la formación crítico/reflexivo del estudiante, un estudiante que, como bien mencionan Arregui et al., (2004), no tome equivocadamente la idea de ser el propio formador de su aprendizaje, sino más bien, que se sienta parte de un mismo equipo, 
donde el docente y la comunidad tengan el mismo protagonismo respecto a la enseñanzaaprendizaje, fortaleciendo el vínculo con el entorno hoy menospreciado.

Desde luego no podemos dejar de mencionar dentro de los problemas educativos el aspecto económico, no solo desde la inversión que el estado proporciona para cada uno de los estudiantes, la misma que, por cierto, está considerada demasiado baja en relación a los países vecinos, sino, además, en la inversión en busca de la disminución de la pobreza, debido a que ello determina y origina a un estudiante preocupado por insertarse en el mundo laboral, dejando de lado el aspecto académico. Con lo cual, podemos concluir que, una buena política educativa, va "conjuntamente con el gasto de bolsillo en educación a nivel del hogar, lo que constituye aspectos limitantes o facilitadores en el acceso a servicios educativos de calidad" (Jopen et al., 2014, p. 5).

Asimismo, el estado peruano tampoco se a preocupado por el aspecto geográfico, articular cada zona alejada del país es pues una carencia y necesidad año tras año, puesto que "las brechas asociadas a la zona de residencia, es decir, las que implican una posición de desventaja para las poblaciones rurales, son muy marcadas y persistentes" (Guadalupe et al., 2017, p. 206), en consecuencia:

El tamaño y la difícil geografía del territorio peruano le han impuesto al Estado un enorme reto para el control centralizado de los servicios (...). Así, el desarrollo de un sistema nacional de educación como objetivo político ha representado y expresado la necesidad de integración impulsada por los dos extremos del espectro nacional: el Estado central basado en Lima, y las comunidades urbanas y rurales del resto el país que buscan diferentes maneras de integrarse a la ciudadanía y el desarrollo (Oliart, 2011, p. 84).

De modo que, la modernización en el Perú solo ha llegado y llega para las grandes ciudades, y pensando en éstas, más aún, esto solo en infraestructura y tecnología, puesto que para la educación, la visión "moderna", no hace más que fosilizar las culturas locales, perdiendo el valor integral y cualitativo de la nación, en ese sentido, lo que se busca es "un conocimiento lo más completo posible del hombre, sin que sus potencialidades o necesidades queden simplemente circunscritas a uno de los ámbitos constitutivos de su compleja naturaleza" (Castillo, 2004, p. 31). 
Debemos tener presente sin embargo que el problema de la modernización no es solo un problema que concierne al Perú, sino a Latinoamérica en su conjunto, la región afronta las mismas dificultades por lo que se ha "promulgado leyes, reformas constitucionales y nuevas constituciones políticas que reconocen en términos positivos la diversidad cultural (...)" (Zapata, 2019, p. 11), teniendo en cuenta que "este conjunto de logros, lejos de ser una concesión por parte de los respectivos Estados, fue el resultado de un proceso de movilización social de envergadura que se inició en los años 60 y que no ha concluido" (Zapata, 2019, p. 11).

\section{CONCLUSIÓN}

El contexto educativo peruano es hasta el presente un problema no resuelto, el recorrido histórico acerca de las políticas educativas a través de los años nos muestra la insistencia por parte del estado en adoptar modelos pedagógicos extranjeros, de los denominados países "desarrollados y modernos", los cuales desde luego, no cuentan con una mirada hacia el Perú profundo, y por el contrario, lo que se hace es potenciar el centralismo y las desigualdades al solo tomar en consideración a los educandos de las grandes ciudades.

Para una educación integral y articulada, es necesario democratizarla y someter al actual paradigma educativo a una crítica constructiva, en la que se modifiquen y se ponga la debida importancia a los aspectos locales, a sus carencias y necesidades. Es imposible hablar de una educación igualitaria, con las mismas oportunidades, si no escuchamos las voces de cada comunidad alejada, si no respetamos su lengua, tradición, costumbre, cultura, historia, etc. Es imposible si el propio Estado no invierte en generar oportunidades en las zonas rurales, si el propio indígena tiene que, a la vez, trabajar y financiar su escuela.

Algún joven estudiante migrado desde el interior del país hacia las grandes ciudades entonces, y con toda razón se podría preguntar, ¿Dónde está la equidad entre peruanos? ¿Cuál debe ser mi modo de vivir y socializar en esta nueva sociedad?, sin duda, se ha dejado a la deriva al estudiante como sujeto, y a la cultura como el todo. Los gobiernos de turno deberían cuestionarse hacia dónde apuntamos como nación, teniendo en claro que, modernizar un país multinacional, sin duda no es la vía, por el contrario, descolonizarnos de los planteamientos occidentales y norteamericanos seguramente nos encaminaría a la universalidad educativa, ésta que es un sueño, una añoranza para el indígena. Entender a 
nuestro país como un estado plurinacional, con seguridad nos encaminará hacia una nueva sociedad, con las mismas oportunidades para todos, sin las brechas hoy latentes.

\section{REFERENCIAS}

Apaza, A. (2016). Breve historia de la educación en el Perú. Revista Apunt. Univ. 6(2), 111124.

Arregui, P., Benavides, M., Cueto, S., Secada, W., Saavedra, J. y Hunt, B. (2004). ¿Es posible mejorar la educación peruana?: evidencias y posibilidades. Lima, Perú: GRADE, Grupo de Análisis para el Desarrollo Editorial.

Barrantes, R. y Peña, J. (Comps.) (2009). El Sistema Educativo durante el proceso de la violencia. Colección Cuadernos para la Memoria Histórica N. 1. IDEHPUCP, Lima.

Castillo, L. (2004). El principio de libertad en el sistema educativo. Piura, Perú: UDEP. Ara Editores.

Dussel, E. (2008). Marx y la modernidad, conferencias de la paz. La Paz, Bolivia: Rincón ediciones.

Garfias, M. (2015). 200 años de Políticas Educativas: de la promesa igualitaria a las prácticas segregacionistas. Revista Argumentos, 9(3), 60-68.

Guadalupe, C., León, J., Rodríguez, J. y Vargas, S. (2017). Estado de la educación en el Perú Análisis y perspectivas de la educación básica, Lima, Perú: Grupo de Análisis para el Desarrollo (GRADE).

Heilman, P. (2018). Rebeliones inconclusas, Ayacucho antes de Sendero Luminoso. Lima, Perú: La siniestra ensayos.

Jopen, G., Gómez, W. y Olivera, H. (2014). Sistema educativo peruano: balance y agenda pendiente Lima, Perú: Cartolán Editora y Comercializadora E.I.R.L.

Maldonado, R.(2016). El Método Hermenéutico en la investigación cualitativa. DOI: 10.13140/RG.2.1.3368.5363 Programa de Magíster en Trabajo Social y Políticas Sociales. Researcher gate.

Mariátegui, J. (2008). Temas de educación. Caracas, Venezuela: Editorial Educación Libertad.

Mariátegui, J. (2007). 7 ensayos de interpretación de la realidad peruana. Caracas, Venezuela: Biblioteca Ayacucho.

Oliart, P. (2011). Políticas educativas y la cultura del sistema escolar en el Perú. Lima, IEP, Tarea, (Educación y Sociedad, 7).

Ramírez, R., Espronceda, H. y Rodríguez, A. (2011). Fortalecer la identidad nacional en los jóvenes: Una razón que no admite espera. OLIMPIA. Revista de la Facultad de Cultura Física de Granma. 8(29), 83-90. 
Rojas, A. (2016). Retos a la Educación Peruana en el Siglo XXI. REICE. Revista Iberoamericana sobre Calidad, Eficacia y Cambio en Educación, 14(1), 101-115.

Rottenbacher, J. (2009). Identidad y la valoración de la historia en una muestra de profesores de la escuela pública de Lima Metropolitana. LIBERABIT: Lima, Perú, 15(2), 75-82.

Sandoval, P. y Agüero, J. (2014). Modernidad y educación en el Perú. Lima, Perú: Serie diversidad cultural 8 Editores, Ministerio de Cultura / Dirección Desconcentrada de Cultura de Cusco Subdirección de Interculturalidad Fondo Editorial.

SINEACE - Sistema Nacional de Evaluación, Acreditación y Certificación de la Calidad Educativa (2011). Educación a lo largo de la vida: medios de articulación en el sistema educativo. Lima, Perú: IPEBA.

Vargas, D. y Pérez, K. (2019). El sistema educativo peruano y la pérdida de identidad cultural andina en la región Puno Rev. Innova Educ. (2019). 1(2), 244-251. https://doi.org/10.35622/j.rie.2019.02.010

Zapata, A. (2016). Pensando a la derecha. Lima, Perú: Editorial Planeta Perú S.A.

Zapata S. (2019). Crisis del multiculturalismo en América Latina: conflictividad social y respuestas críticas desde el pensamiento político indígena. San José, Costa Rica: Editorial UCR. 